\title{
Humidity adsorption kinetics of a trypsin gel film
}

\author{
Salih Okur ${ }^{\mathrm{a}, \mathrm{b}, *}$, Cagatay Ceylan $^{\mathrm{c}}$, Evren Culcular ${ }^{\mathrm{b}}$ \\ ${ }^{a}$ Department of Metallurgy Engineering, Izmir Katip Celebi University, Izmir, Turkey \\ ${ }^{\mathrm{b}}$ Department of Physics, Izmir Institute of Technology, Urla 35430, Izmir, Turkey \\ ${ }^{\mathrm{c}}$ Department of Food Engineering, İzmir Institute of Technology, Izmir, Turkey
}

\section{A R T I C L E I N F O}

\section{Article history:}

Received 16 August 2011

Accepted 28 September 2011

Available online 6 October 2011

\section{Keywords:}

Trypsin

Gelation

Thin film

Humidity

Quartz crystal microbalance

Atomic force microscopy

\begin{abstract}
A B S T R A C T
This study focuses on the humidity adsorption kinetics of an isopropanol-induced and pH-triggered bovine pancreatic trypsin gel (BPTG). The BPTG was adsorbed on a gold coated Quartz Crystal Microbalance (QCM) substrate with a thickness of $376 \mathrm{~nm}$. The morphology of the film was characterized using Atomic Force Microscopy (AFM). QCM was used to investigate the humidity sensing properties of the BPTG film. The response of the humidity sensor was explained using the Langmuir model. The average values of adsorption and desorption rates between $11 \% \mathrm{RH}$ (relative humidity) and $97 \% \mathrm{RH}$ were calculated as $2482.5 \mathrm{M}^{-1} \mathrm{~s}^{-1}$ and $0.02 \mathrm{~s}^{-1}$, respectively. The equilibrium constant and average Gibbs Free Energy of humidity adsorption and desorption cycles were obtained as 133,000 and $-11.8 \mathrm{~kJ} / \mathrm{mol}$, respectively.
\end{abstract}

(c) 2011 Elsevier Inc. All rights reserved.

\section{Introduction}

Modification of surface with natural polymers and proteins using adsorption techniques [1] is a very important issue in materials science and technology for biocompatibility [2] of biomedical devices [3], biosensor [4] and food manufacturing technologies $[5,6]$. Other applications include coating of surfaces for protection against corrosive processes [7] or adverse environmental effects which appears to be important in food packaging [8] and other value-added biological. In all these applications, it is crucial to understand the functional behavior of bio-surfaces.

Protein gelation has been recognized as an outcome of heating process in laboratory experiments and food systems [9]. However, cold gelling systems have also been identified for globular protein systems $[10,11]$. Hydration-dehydration behavior is one of the most critical properties for functional and structural protein integrity; hence, in protein gelation, the way protein molecules interact with water determines their operational properties, such as gelling in foods [12]. In addition, it has been shown that reactional activity of proteins is strongly influenced by the water content and composition of the environment surrounding of the protein molecules. Therefore, it is important to consider the role and amount of water in protein containing systems to use it in sensory and other applications.

* Corresponding author at: Department of Physics, İzmir Institute of Technology, Urla 35430, İzmir, Turkey. Fax: +90 2327507707.

E-mail addresses: salihokur2@gmail.com, salihokur@iyte.edu.tr (S. Okur).
In this work, we have studied the water adsorption-desorption kinetics of a cold protein gel film formed on a gold coated QCM crystal surface. QCM technique has been used for the analysis of the dynamic and equilibrium behavior of humidity adsorptiondesorption processes of the trypsin gel film. QCM technique provides new opportunities to investigate the structural processes in the formation of polymer and protein film formation and their physical properties under different environmental variations such as humidity in combination with other experimental methods [13-19]. In addition, AFM has been used to investigate the morphologic characterization of the film formed.

\section{Materials and methods}

\subsection{Preparation of protein-based thin gel film}

Bovine pancreatic trypsin (BioChemika, cat. number 93610), which was selected as the model protein, is a small globular protein with a molecular weight of about $24 \mathrm{kDa}$ [20]. Trypsin has 223 amino acid residues interconnected by six disulfide bonds as shown in Fig. 1 [21]. Molecular images were produced using the UCSF Chimera package from the Resource for Biocomputing, Visualization, and Informatics at the University of California, San Francisco (supported by NIH P41 RR-01081) [22]. The trypsin thin film was prepared according to the following procedure: Trypsin was dissolved in $1 \mathrm{mM} \mathrm{HCl}$ at a concentration of $50 \mathrm{mg} / \mathrm{ml}$. Isopropanol was added to the protein solution as an inducer of gel formation [23] at a volumetric ratio of $1 / 1$. Finally, $0.1 \mathrm{~N} \mathrm{NaOH}$ was 


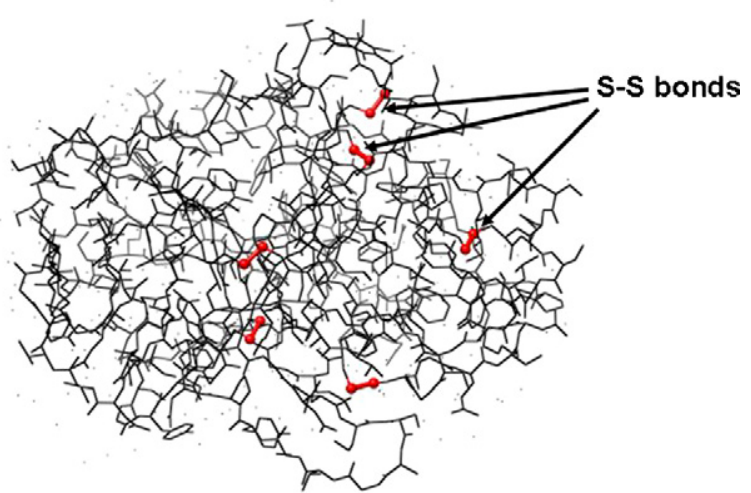

Fig. 1. Bovine pancreatic trypsin and disulfide bonds are depicted as balls connected by sticks (o-o).

added to the protein-isopropanol mixture and applied to the crystal surface. Upon the addition of $\mathrm{NaOH}$, the gelation process was triggered and completed in the first $5 \mathrm{~min}$, resulting in a transparent and stable protein gel film structure. Later, the gel was treated with analytically pure ethanol along with a sonication process for $5 \mathrm{~min}$, leaving a visually observable adhesive layer on the surface of a gold coated QCM electrode. The thickness of the film was measured as $376 \mathrm{~nm}$ with a Dektak Profilometer (Veeco). A Solver Pro AFM (NTMDT) was used to investigate the morphology of the trypsin gel film surface.

\subsection{Humidity measurements}

The change in the resonance frequency of quartz crystals between gold electrodes was measured with a time-resolved research quartz crystal microbalance (RQCM, Maxtek. Inc.). The system operates in a dual frequency range between 3.806.06 $\mathrm{MHz}$, and $5.10-10.00 \mathrm{MHz}$ oscillation frequencies with a frequency resolution of $0.03 \mathrm{~Hz}$ at $6.00 \mathrm{MHz}$ and mass resolution smaller than $0.4 \mathrm{ng} / \mathrm{cm}^{2}$. Hence, $1 \mathrm{~Hz}$ change in frequency corresponds to a $10.2 \mathrm{ng}$ change in mass. Cleaning of the gold coated quartz crystal electrode was carried out in 15 min ultrasonic cleaning cycles with acetone, ethanol, isopropanol and with a final rinse in deionized water. Remaining ethanol and water was removed in by argon gas flow. Frequency readings were obtained after the crystal was placed into its Teflon housing. Humidity standards were provided in a closed box system partially filled with saturated salts with various relative levels between $11 \%$ and $97 \% \mathrm{RH}$. The set up used to observe the hydration-dehydration kinetics of the gel layer using the standard salt solutions was described in details in our previous work [24].

\section{Results and discussion}

QCM experiments were carried out to observe adsorption/ desorption kinetics for increasing and decreasing humidity values between $11 \%$ and $97 \% \mathrm{RH}$. The $\mathrm{RH}$ is varied for equal time of intervals to investigate the kinetics of any residual adsorbed water mass on the protein gel film. The frequency response of the protein gel covered QCM plate during adsorption-desorption cycles between $11 \%$ and $97 \%$ RH as a function of time is shown in Fig. 2a and b. Fig. 2b shows an exponential dependence of QCM frequency change on relative humidity change. The mass uptake obtained from QCM resonance frequency shifts using Sauerbrey model for adsorption between $11 \%$ and $84 \%$ RH values is shown in Fig. 2c.

According to Fig. 2b, adsorption and desorption processes seem to be reversible and show an exponential dependence on relative humidity change.
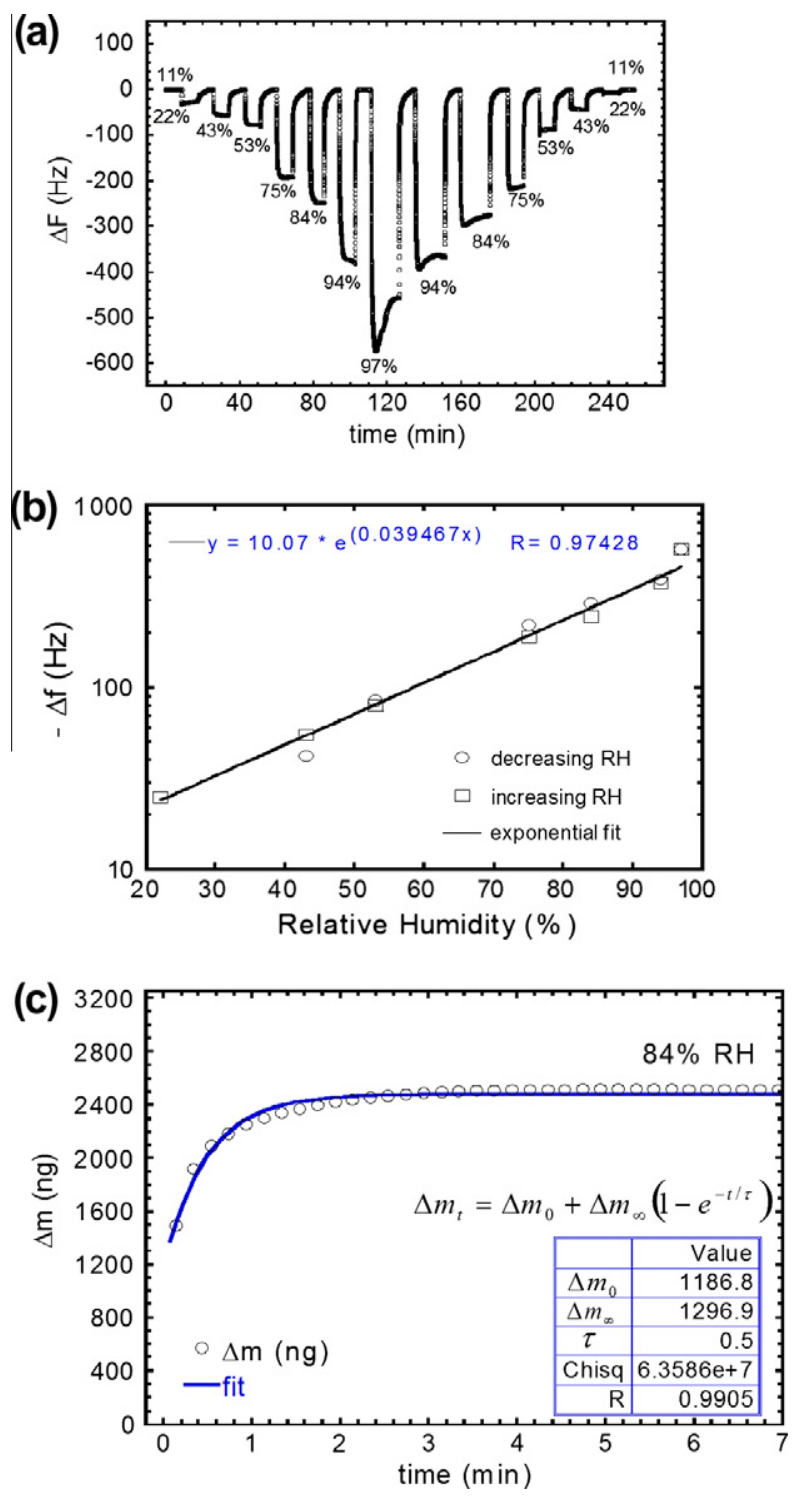

Fig. 2. Mass uptake obtained from QCM resonance frequency shifts using Sauerbrey model for adsorption between $11 \%$ and $84 \% \mathrm{RH}$ values (a), $\mathrm{RH}$ dependence of the frequency changes for adsorption-desorption processes (b), least square fit (dashed line) of the adsorption to the Langmuir adsorption isotherm model given in Eq. (2) (c).

The Langmuir adsorption isotherm model was used to analyze our adsorption data to explain the adsorption-desorption behavior of gas molecules as given in Okur et al. [24]. Basically, the relationship between the surface adsorption rate and frequency shift $(\Delta f)$ QCM can be expressed as

$\frac{d \Delta f}{d t}=\left(\Delta f_{\max }-\Delta f\right) k_{a} C-k_{d} \Delta f$

Ultimately, the time dependence of the change in the frequency for adsorption can be expressed as

$\Delta f(t)=\Delta f_{0}+\Delta f_{\max } K^{\prime}\left(1-e^{-k_{\text {obs }} t}\right)$

The frequency shift is directly proportional to the change in the absorbed mass in the film according to the Sauerbrey relation $\left(\Delta m=-\frac{A \sqrt{\mu \rho}}{2 f_{0}^{2}} \Delta f=-(10.2 \mathrm{ng} / \mathrm{Hz}) \Delta f\right)$ [25]. The change in the mass due to humidity adsorption can be fitted to the Langmuir adsorption isotherm model. The time dependence of the amount of water molecules on the film surface $\Delta m$ can be defined as, 
(a)

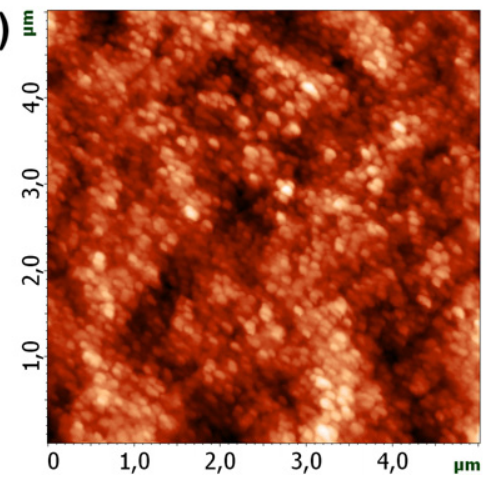

(b)

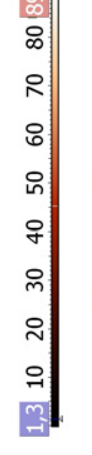

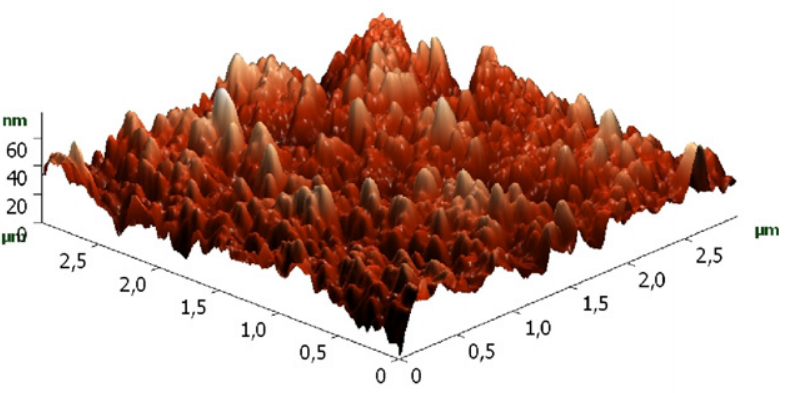

Fig. 3. (a) $2 \mathrm{D}$ AFM view and (b) $3 \mathrm{D}$ AFM view of the trypsin gel film on a gold coated QCM electrode.

$\Delta m_{t}=\Delta m_{0}+\Delta m_{\infty}\left(1-e^{-t / \tau}\right)$

and

$\tau^{-1}=k_{a}[$ molar concentration of water vapor molecules $]+k_{d}$

where $\tau$ is the relaxation time, and $m_{\infty}$ is the maximum amount of the water molecules adsorbed on the surface at $t \rightarrow \infty$ and is obtained as $1296.9 \mathrm{ng}$. The relaxation time of the adsorption process is found as $0.5 \mathrm{~min}$ by the least square fit to Eq. (3).

The average values of adsorption and desorption rates were obtained as $2482.5 \mathrm{M}^{-1} \mathrm{~s}^{-1}$ and $0.02 \mathrm{~s}^{-1}$, from the least square fit of the adsorption part of each cycle, respectively.

The equilibrium constant, $K_{\text {equ }}$, for the adsorption/desorption process of the protein film is obtained with $K_{\text {equ }}=k_{a} / k_{d}$, and the corresponding Gibbs Free Energy for the equilibrium behavior of the process can be calculated in terms of $K_{\text {equ }}$ at constant temperature [26].

$\Delta G=-R T \ln K_{\text {equ }}$

The equilibrium constant and average Gibbs Free Energy of humidity adsorption and desorption cycles were obtained as 133,000 and $-11.8 \mathrm{~kJ} / \mathrm{mol}$, respectively, indicating a spontaneous adsorption process, because $\Delta G$ has a negative sign.

The AFM micrograph, which is shown in Fig. 3, allows the investigation into the overall morphology of the trypsin gel film on gold coated QCM electrodes. Regular nanostructures have been observed after gel formation. This structural organization enables an increase in surface area during the interaction of water molecules (adsorption process).

The results suggest that protein gel film formed on the QCM plate surface is very sensitive to humidity changes and shows a reproducible adsorption/desorption kinetics for short time intervals. The strong binding ability of the protein molecules to the gold surface may be indicative of the disulfide groups found in the structure of trypsin, since the affinity of the sulfide groups to the gold surfaces is well known [27]. Upon treatment with $\mathrm{NaOH}$, trypsin molecules dissolved in the water-isopropanol co-solvent system should be changing their three-dimensional structure in a regular fashion, such that a transparent regular gel network forms. After the gel formation, the removal of the gel bulk is followed by an ethanol wash step and drying. The protein molecules should be subjected to conformational changes in each step as well. Similarly, Lubarsky et al. [19] observed rheological changes in human serum albumin films by changing hydration level. However, their results with a combined AFM and QCM study showed that the mechanical and rheological changes in viscosity, shear, Young's modulus, density and film thickness were reversible.

\section{Conclusions}

The response of isopropanol-induced and alkaline $\mathrm{pH}$-triggered bovine pancreatic trypsin gel film to the relative humidity changes was investigated by QCM technique for various relative humidity values between $11 \%$ and $97 \%$. The Langmuir model was used to determine the adsorption and desorption rates as $2482.5 \mathrm{M}^{-1} \mathrm{~s}^{-1}$ and $0.02 \mathrm{~s}^{-1}$, respectively. The equilibrium constant and average Gibbs Free Energy of humidity adsorption and desorption cycles were obtained as 133,000 and $-11.8 \mathrm{~kJ} / \mathrm{mol}$, respectively. The results show that trypsin as a biomaterial has many advantages, such as large surface area due to nanostructured morphology, reversibility of adsorption/desorption cycles and high sensitivity to environmental $\mathrm{RH}$ changes, for possible humidity sensor applications.

\section{Acknowledgments}

We thank İzmir Institute of Technology (IYTE), Biotechnology and Bioengineering Central Research Laboratories for providing us the necessary facilities throughout the experiments. Trypsin was purchased with funds from IYTE Scientific Research Council (BAP) with the Project numbers 2008IYTE22 and 2010IYTE25. This research was partially supported by DPT (State Planning Organization of Turkey) under Project number DPT2003K120390, and TÜBITAK (Turkish Scientific and Technological Research Council) under Project number TBAG 109T240.

\section{References}

[1] Y. Ikada, Biomaterials 15 (1994) 725

[2] D.L. Elbert, J.A. Hubbell, Annu. Rev. Mater. Sci. 26 (1996) 365.

[3] J. Andrade, V. Hlady, Biopolymers/Non-exclusion HPLC, Springer, Berlin/ Heidelberg, 1986.

[4] A.A. Ansari, P.R. Solanki, B.D. Malhotra, J. Biotechnol. 142 (2009) 79.

[5] P. Sioshansi, Thin Solid Films 118 (1984) 61.

[6] M. Ozdemir, C.U. Yurteri, H. Sadikoglu, Crit. Rev. Food Sci. 39 (1999) 457.

[7] A.S. Svetlana, Biomed. Mater. Eng. 12 (2002) 69.

[8] P. Suppakul, J. Miltz, K. Sonneveld, S.W. Bigger, J. Food Sci. 68 (2003) 408

[9] Y. Wang, J. Tang, B. Rasco, S. Wang, A.A. Alshami, F. Kong, LWT-Food Sci. Technol. 42 (2009) 1174.

[10] C.M. Bryant, D.J. McClements, Trends Food Sci. Technol. 9 (1998) 143.

[11] A.C. Alting, R.J. Hamer, C.G. De Kruif, R.W. Visschers, J. Agric. Food Chem. 51 (2003) 3150.

[12] P.J. Lillford, A.-M. Hermansson, in: D.S. Reid, T. Sajjaanantakul, P.J. Lillford, S. Charoenrein (Eds.), Health, Pharmaceutical and Biological Systems: ISOPOW 10, Wiley-Blackwell, Oxford, UK, 2010. doi:10.1002/9780470958193.ch18.

[13] M. Berglin, A. Olsson, H. Elwing, Macromol. Biosci. 8 (2008) 410.

[14] F. Höök, B. Kasemo, T. Nylander, C. Fant, K. Sott, H. Elwing, Anal. Chem. 73 (2001) 5796.

[15] F. Höök, J. Vörös, M. Rodahl, R. Kurrat, P. Boni, J.J. Ramsden, M. Textor, N.D. Spencer, P. Tengvall, J.E.A. Gold, Colloid Surf. B 24 (2002) 155.

[16] L.E. Bailey, D. Kambhampati, K.K. Kanazawa, W. Knoll, C.W. Frank, Langmuir 18 (2002) 479. 
[17] T.P. Vikinge, K.M. Hansson, P. Sandstrom, B. Liedberg, T.L. Lindahl, I. Lundstrom, P. Tengvall, F. Höök, Biosens. Bioelectron. 15 (2000) 605.

[18] J. Vörös, Biophys. J. 87 (2004) 553.

[19] G.V. Lubarsky, M.R. Davidson, R.H. Bradley, Biosens. Bioelectron. 22 (2007) 1275

[20] L.W. Cunningham Jr., J. Biol. Chem. 211 (1954) 13.

[21] H. Neurath, in: C.B. Anfinsen Jr., M.L. Anson, K. Baıley, J.T. Edsall (Eds.), Advances in Protein Chemistry, vol. 12, Academic Press Inc., New York, 1957, p. 319.
[22] E.F. Pettersen, T.D. Goddard, C.C. Huang, G.S. Couch, D.M. Greenblatt, E.C. Meng, T.E. Ferrin, J. Comput. Chem. 25 (2004) 605

[23] K. Ishino, S. Kudo, Agric. Biol. Chem. 41 (1977) 1347.

[24] S. Okur, M. Kuş, F. Özel, V. Aybek, M. Yılmaz, Talanta 81 (2010) 248.

[25] G. Sauerbrey, Z. Phys. 155 (1959) 206.

[26] S. Qiu, L. Sun, H. Chu, Y. Zou, F. Xu, N. Matsuda, Thin Solid Films 517 (2009) 2905.

[27] V.N. Losev, E.V. Elsufev, E.V. Buiko, A.K. Trofimtchukb, E.V. Andrianovab, Mendeleev Commun. 14 (2004) 24 